\title{
Cue hierarchy and foraging in calanoid copepods: ecological implications of oceanographic structure
}

\author{
C. B. Woodson ${ }^{1,3, *}$, D. R. Webster ${ }^{1}$, M. J. Weissburg ${ }^{2}$, J. Yen ${ }^{2}$ \\ ${ }^{1}$ School of Civil and Environmental Engineering, and ${ }^{2}$ School of Biology, Georgia Institute of Technology, \\ Atlanta, Georgia 30332, USA \\ ${ }^{3}$ Present address: Department of Oceanography, University of Hawai'i at Manoa, Honolulu, Hawai'i 96822, USA
}

\begin{abstract}
Fine-scale water column structure was mimicked in a laboratory plane jet flume to examine responses of the calanoid copepods Temora longicornis and Acartia tonsa to layers consisting of a velocity gradient, density gradient, phytoplankton exudates and food (phytoplankton). Copepods were exposed to isolated layers and combinations of cues as defined by in situ conditions. Behaviors elicited by the velocity gradient and chemical exudate layers included increased swimming speed and turn frequency consistent with excited area-restricted search behavior, which led to increased proportional residence time in the layers. Both species had significant responses to isolated layers of velocity gradients and chemical exudates, with $T$. longicornis responding more intensely to chemical cues than velocity gradients and $A$. tonsa responding equally to both. Combined fluid mechanical and chemical cues elicited species-specific responses. For T. longicornis, chemical presence induced responses that strengthened or cancelled initial reactions to the velocity gradient. These results suggest a cue hierarchy where a velocity gradient acts as an initial cue for narrowing search regions, and chemical cues and food presence determine consequent responses. For $A$. tonsa, combining velocity gradient and chemical cues had the same effect on copepod behavior as the individual cues, which suggests both cues are equal sources of information but are not closely associated. In both species, physical contact with particles or cells initiated feeding behavior, resulting in lower swimming speeds. Fluid density had a potentially aversive effect, as neither species responded with an area-restricted search response and individuals rarely crossed a strong density gradient. Observed behaviors may lead to aggregation, especially when superimposed on rhythmic movements such as diel vertical migration.
\end{abstract}

KEY WORDS: Copepod $\cdot$ Temora longicornis $\cdot$ Acartia tonsa $\cdot$ Foraging cues $\cdot$ Proportional residence time $\cdot$ Behavior

Resale or republication not permitted without written consent of the publisher

\section{INTRODUCTION}

Zooplankton aggregations have been observed near thin layers (high concentration patches in the water column on the order of $1 \mathrm{~m}$ thick vertically which can span several square kilometers and last for several days) and other oceanographic structures such as steep velocity and density gradients (Mackas \& Louttit 1988, Widder et al. 1999, Dekshenieks et al. 2001, Holliday et al. 2003). The association of peaks in biological activity (primary production and consumers) with these gradients suggests that both physical forcing (patterns cre- ated by physical properties) and individual behavioral responses to these physical and biological features play important roles in defining observed in situ patterns of animal distributions (Cowles 2004, Gallager et al. 2004, McManus et al. 2005). Hypotheses about the important processes controlling distribution and patchiness at larger scales ( e.g. meters to kilometers, days) by physical forcing are relatively well accepted, although exact mechanisms are still largely untested (reviewed in Franks 1995). Conversely, the relative importance of these gradients or patches with respect to zooplankton behavior is not well understood, especially at the indi- 
vidual level, although recent advances have greatly improved our understanding. Increased resolution in field observations has shown that zooplankton aggregate at fine-scale structure (Holliday et al. 1998, McManus et al. 2005), while modeling studies support views that these aggregations result from zooplankton behavior (Leising \& Franks 2000, Leising 2001). However, the cues and mechanisms behind aggregation development and maintenance remain elusive.

Zooplankton survival is directly linked to their ability to locate high resource patches (Bainbridge 1953, Mullin \& Brooks 1976, Daro 1988). Hence, fine-scale oceanographic features associated with ephemeral food patches can affect the fitness of these organisms. At larger ecological scales, copepod foraging efficiency, grazing rate and aggregation are known to affect and in some cases drive phytoplankton abundance and nutrient cycling in many systems (Landry et al. 1994, Hansen et al. 1999, Turner 2004). Thus, the behavior of copepods at the individual level can have widespread effects on many ecological processes.

Several questions must be answered in order to determine whether fine-scale oceanographic structure is behaviorally important to copepods. (1) Is relevant, reliable information about the local environment contained within thin layers (persistent regions of high productivity on the order of $1 \mathrm{~m}$ thick vertically) and other oceanographic features? Due to the close association of in situ gradients with biological activity, physical gradients (if detectable) might serve as a proximal cue for biologically relevant properties (e.g. food; Cowles 2004). (2) Is this information perceivable by plankters? Several species of copepods are known to respond to the presence of velocity gradients, density discontinuities and chemical compounds (Harder 1968, Poulet \& Marsot 1978, Yen \& Fields 1992). Additionally, reported strain rate levels associated with in situ peaks in chlorophyll concentration fall in a range between physiological detection limits and escape response thresholds (Titelman 2001, Fields et al. 2002, Cowles 2004). (3) Is some benefit or advantage acquired by using the associated information? Previous studies suggest that zooplankton are able to use fine-scale discontinuities and patches in the water column to improve foraging efficiency and aggregate (Harder 1968, Hamner 1988, Woodson et al. 2005), which, it has been argued, increases individual fitness. However, direct assessments of the impacts of patchiness on copepod fitness are inconclusive (Tiselius 1992, Saiz et al. 1993, Bochdanksy \& Bollens 2004).

The aim of this study is to determine the potential ability of copepods to use various cues associated with oceanographic structure and examine which cues convey information. To do so, we examined the behavioral responses of individuals of 2 calanoid copepod species,
Temora longicornis and Acartia tonsa, to layers of velocity gradients, density gradients (as salinity), phytoplankton chemical exudates, phytoplankton (food) concentration and combinations of these cues in conditions that mimic field observations of oceanographic structure.

\section{MATERIALS AND METHODS}

A laminar plane jet flume was used to generate model layers of oceanographic properties such as velocity gradient, density gradient (as salinity), and biological activity. Full details and a sketch of the apparatus are provided in Fig. 1 and Woodson et al. (2005). This experimental apparatus $(100 \times 30 \times 30 \mathrm{~cm})$ was used for both layer characterization and behavioral experiments. The $y$-axis is the vertical dimension and corresponds to the typical oceanographic notation of depth as the $z$-axis.

Layer characterization. All parameters and techniques for the velocity and density gradient layers are described in Woodson et al. (2005) along with a detailed description of the methods for layer characterization (particle image velocimetry [PIV] and planar laser-induced fluorescence [PLIF]). In the present study, the chemical exudate and food layers were also quantified using the PLIF technique. In this case, Rhodamine 6G was used as a surrogate for the chemical exudates or food. Rhodamine 6G was not present during behavioral experiments and was used only for characterization of the model layer.

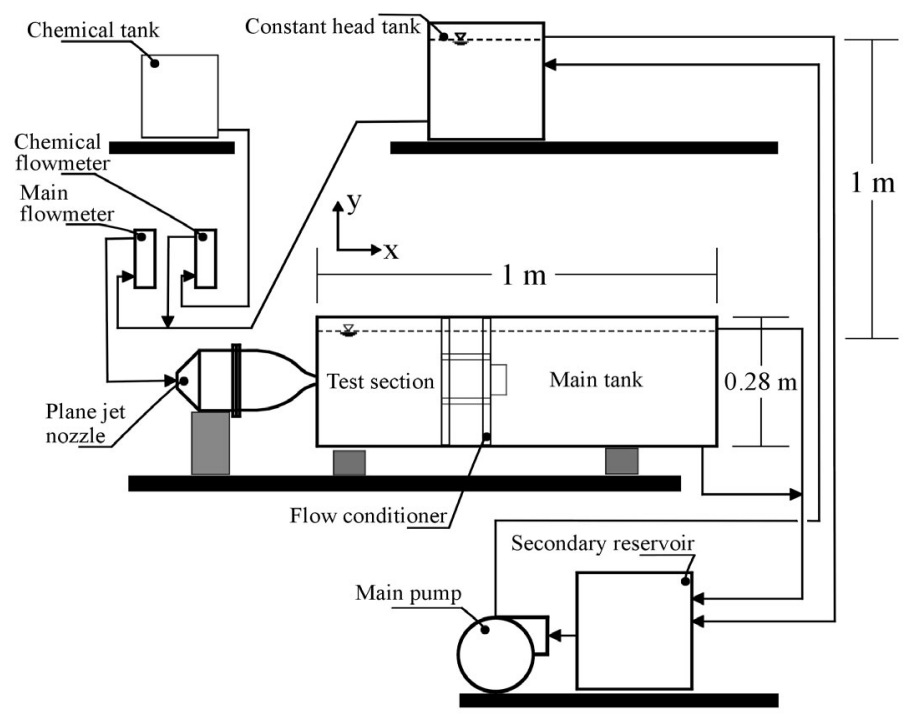

Fig. 1. Schematic representation of the experimental apparatus. Coordinate axes are shown with the $x$-axis in the horizontal direction aligned with the direction of flow, the $y$-axis in the vertical direction, and the $z$-axis oriented perpendicular to the sketch 
Food and chemical gradient layers were created by advection (transport by fluid flow) of odor or food laden water across the test section and then stopping the jet flow after an interval sufficient for the dye to advect across the experimental section of the tank. The jet momentum was then allowed to dissipate for approximately $10 \mathrm{~min}$ before measurements. Chemical exudates, food or dye (for visualization and layer characterization) were fully mixed into the main jet flow by introducing these substances to the jet fluid upstream of the flow conditioning section. Concentration in the layer was calculated from the flow rate and concentration of the secondary stream using mass conservation techniques and later validated through PLIF experiments. Examination of concentration distributions (see Fig. 2) revealed that this technique allowed the creation of a distinct chemical layer in the middle of the test section without the use of a density gradient as employed in several previous studies of patchiness (e.g. Tiselius 1992, Bochdansky \& Bollens 2004, Clay et al. 2004). Consequently, we tested the behavioral effect of chemical cues without the confounding effects of density gradients.

Layers with combinations of the constituents were created in addition to the isolated layer treatments. The velocity-chemical layer used the main flow in combination with the secondary stream (dye, phytoplankton or phytoplankton exudates). The reservoir water was not recirculated in these trials to prevent concentration increases in the model layer during the experiments. The velocity-density model layer was created by filling the tank to just over half full with 30 ppt salinity artificial seawater. Denser ( $\geq 30$ ppt salinity) seawater was then pumped into the tank through the drain fitting until the density jump was aligned with the bottom of the jet nozzle $(0.5 \mathrm{~cm}$ below the mid-point of the tank). The plane jet fluid (30 ppt salinity) flowed with an exit velocity of $6.7 \mathrm{~mm} \mathrm{~s}^{-1}$, matching the velocity-only layer experiments. The density-chemical layer was created by first filling the tank with a density gradient at mid-depth, then advecting the chemical solution across the tank as in the chemical- or food-only layer treatments. Once the chemical layer passed through the test-section region, both pumps were turned off, and residual momentum was allowed to dissipate. Finally, the velocity-density-chemical layer was created in the same fashion, except the jet continued to flow with no recirculation.

Behavioral experiments. Temora longicornis were collected from Stony Brook Harbor (New York, USA) and the Gulf of Maine. Acartia tonsa were collected from Wassaw Sound near Skidaway Island, Georgia, USA. After overnight transport to Atlanta, Georgia, copepods were sorted and stored in 191 buckets in an environmental room at constant temperature (12 \pm $0.2^{\circ} \mathrm{C}$ ) for a minimum of $48 \mathrm{~h}$ during which copepods were observed to feed and produce eggs. Copepod cultures were fed either Tetraselmis sp. (Chlamydomonadaceae, green flagellate) or Rhodomonas lens (Cryptophyceae, red flagellate) under saturating conditions every few days. Copepods were not fed during the $24 \mathrm{~h}$ before behavioral experiments. All experiments were subsequently conducted at constant temperature (12 \pm $0.2^{\circ} \mathrm{C}$ ) using artificial seawater. Although capture, shipping, and storage of organisms before experiments may have altered behavioral responses, studies conducted nearshore within $4 \mathrm{~h}$ of copepod capture showed similar results (Woodson et al. 2005), suggesting that transport and handling were not significantly affecting behavior in the laboratory.

Behavioral experiments consisted of treatment layers of (1) control (homogenous seawater, stagnant fluid); (2) velocity gradient $\left(U_{j}=6.7 \mathrm{~mm} \mathrm{~s}^{-1}\right.$, strain rate = $0.50 \mathrm{~s}^{-1}$ max in the observation region, Woodson et al. 2005); (3) density gradient (2 ppt salinity change); (4) phytoplankton chemical exudates (253 $\mu \mathrm{g} \mathrm{C} \mathrm{l}^{-1}$ equivalent); (5) velocity and density; (6) velocity and chemical exudates; (7) density and chemical exudates (8) velocity, density and chemical exudates; and (9) phytoplankton $\left(253 \mu \mathrm{g} \mathrm{C}^{-1}\right)$ (Table 1$)$. A range of density gradients $(0,0.25,0.5,0.75,1,2$, and 4 ppt salinity change, corresponding to $0,0.2,0.4,0.8,1.6$, and 3.1 $\Delta \sigma_{t}$, density change, respectively) and chemical exudates concentrations $(0,32,64,95,126,158$,

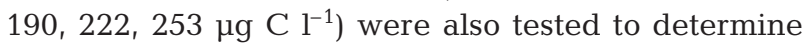
threshold response levels to these cues. Similar tests were not performed for the velocity gradient treatment because other methods have been employed to estimate behavioral threshold response levels to shear strain rate $\left(0.03\right.$ to $0.06 \mathrm{~s}^{-1}$ for Temora longicornis; 0.035 to $0.06 \mathrm{~s}^{-1}$ for Acartia tonsa; Woodson et al. 2005). Concentrations used in the food and chemical layer experiments matched field measurements (Cowles 2004) showing peak concentrations of $15 \mathrm{mg} \mathrm{chl} \mathrm{a} \mathrm{m}{ }^{-3}$ (equivalent to $\sim 10000$ cells $\mathrm{ml}^{-1}$, or $230 \mu \mathrm{g} \mathrm{Cl}^{-1}$ ) in thin layers and background concentrations around $2 \mathrm{mg}$ chl a m $\mathrm{m}^{-3}\left(\sim 1000\right.$ cells ml $\mathrm{ml}^{-1}$, or $\left.20 \mu \mathrm{g} \mathrm{Cl}^{-1}\right)$. Additionally, copepods were exposed to a velocity-all chemical layer treatment, in which the velocity gradient was created with the entire water column (and the jet) at a homogenous exudate concentration (253 $\mu \mathrm{g} \mathrm{C} \mathrm{l}^{-1}$ equivalent). This treatment allowed us to assess if background chemical presence influenced the response to the velocity gradient. Two replicates were performed for each treatment and 50 observations were taken from each replicate for analysis.

Food layer and chemical exudate layer treatments were prepared from separate Tetraselmis sp. and Rhodomonas lens cultures. Phytoplankton cultures were maintained at optimal growth temperature (22 to $25^{\circ} \mathrm{C}$ ) on marine culture media (Sigma Guillard's 
[f/2] \#G0154) and artificial seawater. Turnover of cultures and media occurred every $2 \mathrm{~d}$. Cytometer cell counts were conducted during each water exchange to verify that cultures were in exponential growth phase. Cells were counted directly before experiments using exudates or food to establish cell density, and cell size was measured for 10 ind. Cell volume was estimated at $105 \pm 5$ and $200 \pm 8 \mu^{3}$ for Tetraselmis sp. and $R$. lens, respectively. Carbon concentration was estimated based on the empirical formula given by Menden-Deuer \& Lessard (2000). For the food layer experiments, phytoplankton cultures were introduced to the apparatus following the procedures described above for chemical layer characterization using a gravity feed instead of a pump to prevent cell lysis. For chemical exudate layers, phytoplankton cultures were centrifuged (3000 rpm or $\sim 10 \times g, 23^{\circ} \mathrm{C}, 5 \mathrm{~min}$ ), filtered through a $0.7 \mu \mathrm{m}$ glass fiber filter and introduced to the apparatus following the methods described above.

Species-specific groups of 60 to 70 adult, mixed-sex copepods were added to the test section of the tank, allowed to acclimate for $2 \mathrm{~h}$ and aggregated at either the water surface or the tank bottom using a fiber optic light source until the beginning of the experiment. The fiber optic light was turned off as the experiment began, and illumination for video recording was provided by infrared diodes. Temora longicornis and Acartia tonsa did not respond to light in the infrared wavelengths (Stearns \& Forward 1984, authors' pers. obs.). A mesh filter $(50 \mu \mathrm{m})$ at the downstream end of the tank prevented individuals from recirculating through the system during flow experiments. Individual interactions with the layer treatments in a $10 \times 10 \mathrm{~cm}$ observa- tion region were recorded on videotape (S-VHS) using a closed coupled device (CCD) video camera (Pulnix model TM-745, $768 \times 494$ pixels). Most copepods were located in the rear section of the test tank at the end of experiments, suggesting that individuals were not recorded more than once (Woodson et al. 2005).

Fifty individual paths from the S-VHS recordings of each trial were digitized using ExpertVision software (MotionAnalysis) at $15 \mathrm{~Hz}$ for kinematic analysis of swimming speed and turn frequency. The duration of recorded paths typically was approximately $60 \mathrm{~s}$. The frame rate was selected because copepod swimming displacement corresponded to approximately 1 pixel between images so that swimming speed calculations were independent of the frame rate in this range, but subtle changes in swimming speed could be detected. Relative swimming speed was reported for all layers containing a velocity gradient and was calculated by subtracting the fluid velocity vector from the swimming vector at each location (see Woodson et al. 2005). For density layer experiments, we also recorded whether the individual crossed the gradient layer for the first 40 paths.

Paths that did not contact the gradient layer and paths with escape responses were removed from the data set resulting in a loss of between 0 and 15 paths per experiment. Data collection consisted of calculating proportional residence time (PRT), pre- and postcontact swimming speeds, and pre- and post-contact turn frequency for each individual path. PRT was defined as the ratio of the time spent in the layer region to the total time in the field of view. A turn event was defined as a change in the 2-dimensional swimming trajectory of $>15^{\circ}$ during a period of $0.33 \mathrm{~s}$. Animal

Table 1. List of treatment names, notations and stimuli presented. Treatments 1 to 8 were conducted as part of the hierarchy experiment and tested using a nested ANOVA. Treatments 9 to 12 were conducted separately and are shown in the table for reference. Two replicates were performed for each treatment with 50 paths recorded from each replicate. Experiments were conducted in random order with different copepod specimens

\begin{tabular}{|c|c|c|c|}
\hline $\begin{array}{l}\text { Treatment } \\
\text { no. }\end{array}$ & Treatment & $\begin{array}{l}\text { Treatment } \\
\text { notation }\end{array}$ & Stimuli presented \\
\hline 1 & Control & $\mathrm{CN}$ & None \\
\hline 2 & Velocity & $\mathrm{V}$ & Velocity gradient only \\
\hline 3 & Density & $\mathrm{D}$ & Density change only \\
\hline 4 & Chemical & $\mathrm{C}$ & Chemical exudates only \\
\hline 5 & Velocity-density & VD & Velocity gradient and density change \\
\hline 6 & Velocity-chemical & $\mathrm{VC}$ & Velocity gradient and chemical exudates \\
\hline 7 & Density-chemical & $\mathrm{DC}$ & Density change and chemical exudates \\
\hline 8 & $\begin{array}{l}\text { Velocity-density-chemical } \\
\text { (All combined) }\end{array}$ & VDC & Velocity gradient, density change, and chemical exudates \\
\hline 9 & Food & Fd & Phytoplankton only \\
\hline 10 & Velocity-all chemical & $\mathrm{V}-\mathrm{AC}$ & $\begin{array}{l}\text { Velocity gradient with homogenous background } \\
\text { concentration of exudates }\left(253 \mu \mathrm{g} \mathrm{Cl}^{-1}\right)\end{array}$ \\
\hline 11 & Density thresholds & - & Range of density changes between 0 and $3.1 \Delta \sigma_{t}$ \\
\hline 12 & Chemical thresholds & - & Range of chemical exudate concentrations between 0 and $253 \mu \mathrm{g} \mathrm{Cl}^{-1}$ \\
\hline
\end{tabular}


locations were calculated based on the centroid and positions could be located with a resolution of less than a pixel. This method removed pixel locking issues from the turn calculations.

Multi-way nested analysis of variance (ANOVA) was used with PRT as the dependent variable to examine individual and interactive effects of velocity, density, and chemical exudate factors. Each main factor possessed 2 fixed levels (present or not present for cues) yielding 1 degree of freedom for each factor and each interaction. Each combination had 2 nested replicates with 50 samples each. In the nested design, replicate effects were not significant (Temora longicornis, $\mathrm{df}=8$, $F=0.55, \mathrm{p}=0.46 ;$ Acartia tonsa, $\mathrm{df}=8, F=0.32, \mathrm{p}=$ $0.62)$; therefore, replicates were pooled and a multiway ANOVA with interactions was performed (see Table 2) with the pooled error variance. This design allowed the evaluation of the effects of both isolated and combined factors. PRT was not transformed since examinations of skewness and kurtosis revealed no evidence that distributions were not normal (Zar 1999).

Single factor ANOVA was used to determine whether significant differences in PRT occurred as a function of chemical concentration or density jump. Posthoc Dunnett's Control tests (D-C) were used to identify where significant differences in PRT occurred for incremental steps in chemical concentration or density jump compared with control values. Non-linear regression techniques revealed qualitatively similar results. The effect of different density steps on swimming behavior was evaluated by regressing the number of layer crossings as a function of the magnitude of the density step.

Statistical comparisons of swimming speed and turn frequency were conducted using a repeated-measures ANOVA design to compare pre- and post-contact values separately for each treatment, with a false discovery rate (FDR) correction due to the large number of tests (Benjamini \& Hochberg 1995). The FDR calculation was based on the results pooled across species, allowing us to statistically compare the response of each species with similar treatments. Kinematic parameters in controls (no gradients) are provided for qualitative comparison. We employed the repeated-measures design to alleviate bias due to varying sex ratios, starvation level and animal condition between experiments (e.g. males typically swim faster than females, Mauchline 1998).

\section{RESULTS}

\section{Layer characterization}

Characterization of the isolated chemical layer is shown in Fig. 2. Isolated velocity gradient and density gradient layers were previously defined in Woodson et al. (2005). Planar fields for all physical and chemical quantities have been measured (e.g. our Fig. 2, Woodson et al. 2005). Fig. 3 shows the velocity, shear strain rate $\left(\frac{1}{2}\left(\frac{\partial u}{\partial y}+\frac{\partial v}{\partial x}\right)\right.$, where $u$ is the horizontal velocity, $v$ is the vertical velocity, $x$ is the horizontal coordinate and $y$ is the vertical coordinate), density, and normalized concentration profiles at $x=100 \mathrm{~mm}$ (center of the field of view) for the combined velocity-density-chemical layer treatment. Profiles for the other combined layers
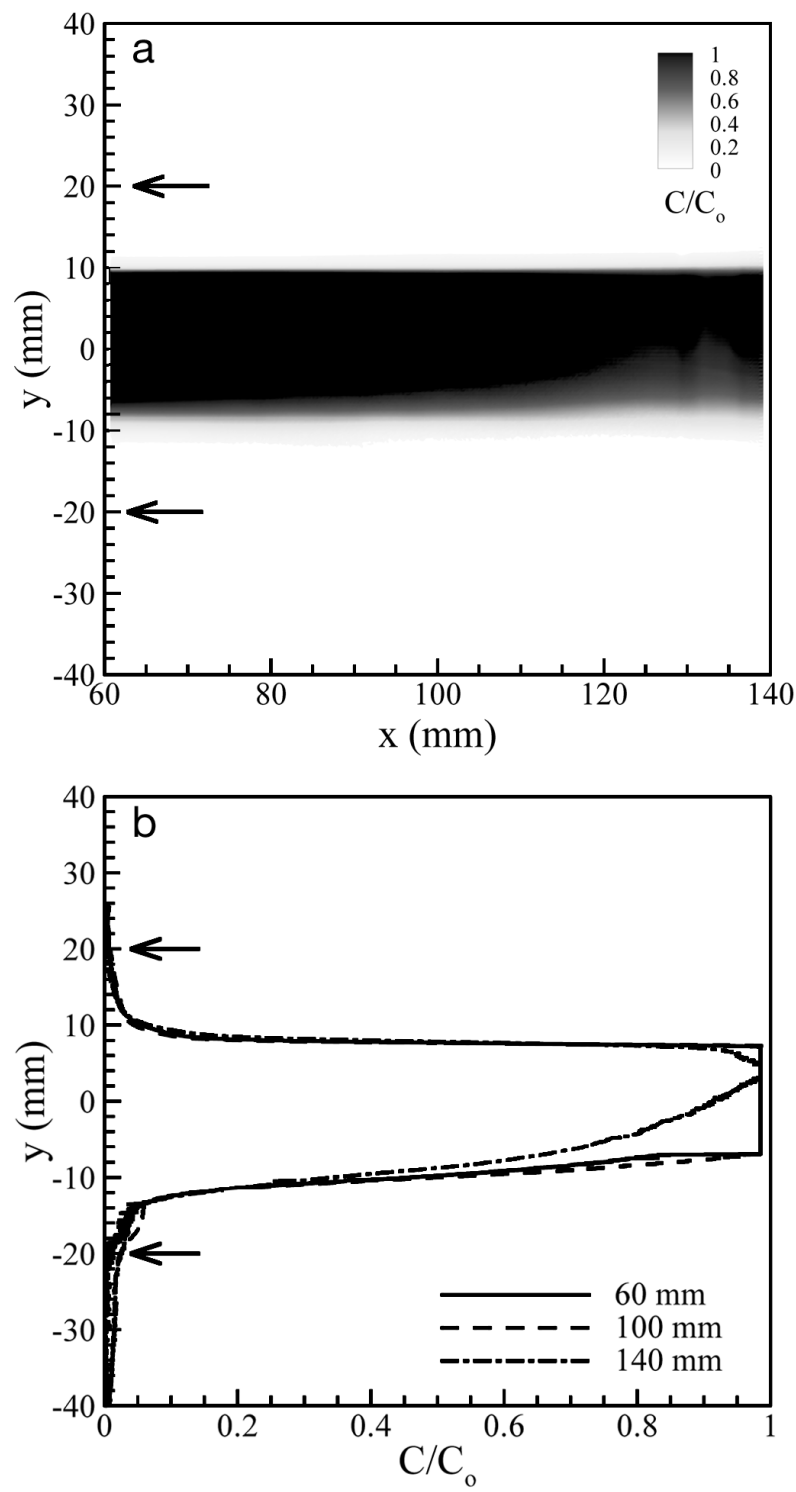

Fig. 2. (a) Concentration field and (b) concentration profiles for the chemical or food layer. Contours show the non-dimensional concentration of Rhodamine $6 \mathrm{G}$ as a surrogate for chemical exudates concentration or phytoplankton cell density. Arrows indicate the edge of the layer defined by $0.025 \mathrm{~s}^{-1}$ shear strain rate threshold. $\mathrm{x}$ and $\mathrm{y}$ are the horizontal and vertical coordinates, respectively; $\mathrm{C} / \mathrm{C}_{\mathrm{o}}$ is the concentration normalized by the source concentration 


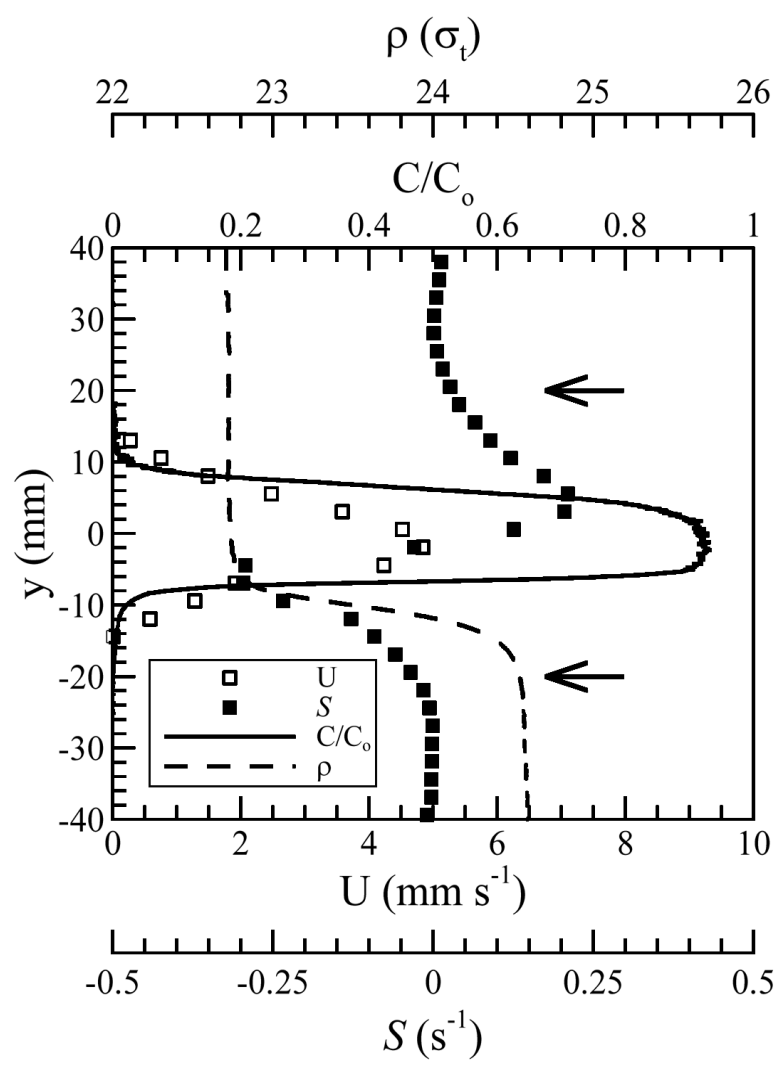

Fig. 3. Velocity, shear strain rate, density and concentration profiles at $x=100 \mathrm{~mm}$ for the combined velocitydensity-chemical layer. Arrows: edge of layer defined by $0.025 \mathrm{~s}^{-1}$ shear strain rate threshold; $y$ : vertical coordinate; $\rho$ : fluid density; $\mathrm{U}$ : fluid velocity; $S$ : shear strain rate; $\mathrm{C} / \mathrm{C}_{\mathrm{o}}$ : concentration normalized by the source concentration

were similar. The density gradient caused the lower portion of the velocity profile to possess a slightly steeper gradient resulting in higher shear strain rates below $y=0 \mathrm{~mm}$ (Fig. 3), but the maximum strain rate level was still below reported escape response thresholds $\left(0.50 \mathrm{~s}^{-1}\right.$, Fields \& Yen 1997). The velocity and shear strain rate profiles were broader than the chemical concentration profile, as expected, because momentum diffuses faster than chemical concentration (kinematic viscosity of $\sim 10^{-6} \mathrm{~m}^{2} \mathrm{~s}^{-1}$ compared with diffusivity of $\sim 10^{-9} \mathrm{~m}^{2} \mathrm{~s}^{-1}$, Fig. 3).

The boundaries of the shear strain rate profile $\left(0.025 \mathrm{~s}^{-1}\right)$ were used to define the layer thickness in all treatments because this definition encompasses all layers defined by other constituents (density gradient, chemical exudates or food). This common definition of the layer region through all behavioral experiments removed bias due to changes in layer width (Woodson et al. 2005). Importantly, the layer was much larger $(\sim 4 \mathrm{~cm})$ than a copepod $(\sim 0.1 \mathrm{~cm})$, ensuring that an individual cannot sense both boundaries of the layer at the same time.

\section{Behavioral experiments}

PRT in the absence of a treatment is expected to be around 0.39 because the layer covers this proportion of the field of view (PRTs for control were 0.34 and 0.39 for Temora longicornis and Acartia tonsa, respectively). An ANOVA indicated that PRT increased significantly in response to the velocity gradient and chemical exudate layers for both species and to the density gradient layer for $T$. longicornis (Fig. 4, Table 2). Interactive effects of the different layer constituents were also assessed in the multi-way ANOVA design. Such effects were significant only in treatment combinations that paired chemical exudates with one of the physical gradients (velocity or density) (Fig. 4, Table 2). For T. longicornis, the presence of chemical layers increased PRT when combined with density or velocity relative to the PRT reached when cues were presented individually. However, A. tonsa did not show increases in PRT for the combined layers and actually showed decreased PRT for the velocity-chemical combined layer compared with the isolated veloc-

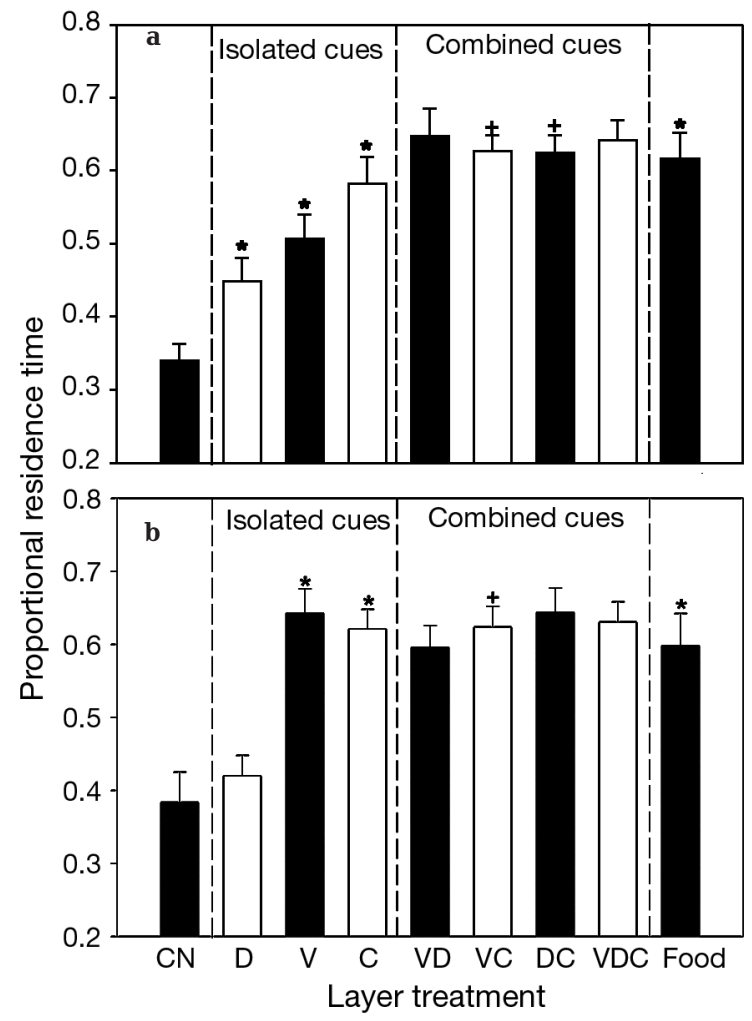

Fig. 4. Proportional residence time for (a) Temora longicornis and (b) Acartia tonsa in the presence of individual and combined cue layers. Treatment notations are defined in Table 1. *Significant effect of single treatments relative to the control as determined with a multi-way ANOVA $(\mathrm{p}<0.05)$. For combined cues, + indicates significant interactive effects between the layer constituents 
Table 2. Results of multi-way ANOVA with 3 main factors (velocity, density and chemical exudates) and interactions with proportional residence time as the dependent factor. Each main factor had 2 fixed levels in the analysis (present or not present). Significance at ${ }^{*} \mathrm{p}<0.05$ and ${ }^{* *} \mathrm{p}<0.001$. Acartia tonsa data show adjusted values due to differences in sample sizes. Seq.: sequential; Adj.: adjusted; -: no value

\begin{tabular}{|c|c|c|c|c|c|c|c|}
\hline $\begin{array}{l}\text { Temora longi } \\
\text { Factor }\end{array}$ & \multicolumn{4}{|c|}{ Temora longicornis } & MS & $F$ & $\mathrm{p}$ \\
\hline Total & & 799 & & & & & \\
\hline Velocity (V) & & 1 & & 1.957 & 1.957 & 46.46 & $<0.001^{* *}$ \\
\hline Density (D) & & 1 & & 0.935 & 0.935 & 22.20 & $<0.001^{* *}$ \\
\hline Chemical (C) & & 1 & & 3.066 & 3.066 & 72.78 & $<0.001^{* *}$ \\
\hline $\mathrm{V} \times \mathrm{D}$ & & 1 & & 0.008 & 0.008 & 0.19 & 0.665 \\
\hline $\mathrm{V} \times \mathrm{C}$ & & 1 & & 0.881 & 0.881 & 20.90 & $<0.001^{* *}$ \\
\hline $\mathrm{D} \times \mathrm{C}$ & & 1 & & 0.359 & 0.359 & 8.54 & $0.003^{*}$ \\
\hline $\mathrm{V} \times \mathrm{D} \times \mathrm{C}$ & & 1 & & 0.022 & 0.022 & 0.53 & 0.466 \\
\hline Error & & 792 & & 33.115 & 0.0418 & - & - \\
\hline $\begin{array}{l}\text { Acartia tonsa } \\
\text { Factor }\end{array}$ & $\mathrm{df}$ & & Seq. SS & Adj. SS & Adj. MS & $F$ & $\mathrm{p}$ \\
\hline Total & 749 & & 39.823 & & & & \\
\hline Velocity (V) & 1 & & 3.119 & 2.314 & 2.314 & 52.93 & $<0.001^{* *}$ \\
\hline Density (D) & 1 & & 0.311 & 0.092 & 0.092 & 2.12 & 0.146 \\
\hline Chemical (C) & 1 & & 1.789 & 2.111 & 2.111 & 48.29 & $<0.001^{* *}$ \\
\hline $\mathrm{V} \times \mathrm{D}$ & 1 & & 0.141 & 0.039 & 0.039 & 0.90 & 0.342 \\
\hline $\mathrm{V} \times \mathrm{C}$ & 1 & & 2.016 & 2.095 & 2.095 & 47.93 & $<0.001^{* *}$ \\
\hline $\mathrm{D} \times \mathrm{C}$ & 1 & & 0.032 & 0.042 & 0.042 & 0.96 & 0.328 \\
\hline $\mathrm{V} \times \mathrm{D} \times \mathrm{C}$ & 1 & & 0.053 & 0.053 & 0.053 & 1.22 & 0.269 \\
\hline Error & 742 & & 32.129 & 32.129 & 0.044 & - & - \\
\hline
\end{tabular}

ity gradient treatment. Neither T. longicornis nor $A$. tonsa showed an increase in PRT in the layer for the velocity-all chemical treatment compared with the control ( T. longicornis, PRT $=0.419$; $\mathrm{df}=99, F=1.33$, $\mathrm{p}=0.251 ;$ A. tonsa, PRT $=0.386 ; \mathrm{df}=99, F=1.13, \mathrm{p}=$ 0.545 ; single-factor ANOVA), suggesting that the background presence of chemical exudates preempted the response to the velocity gradient.

Temora longicornis and Acartia tonsa were tested with a range of density jumps and exudate concentrations to establish threshold responses. Single-factor ANOVA revealed significant differences in the PRT for the range of density gradients $(\mathrm{df}=299, F=2.41, \mathrm{p}=$ 0.036) in $T$. longicornis, and a post-hoc D-C test revealed significant increases from control values at density steps above $\Delta \sigma_{t}=1.6$ (Fig. 5; minimum significant difference, $\left.\mathrm{MSD}_{0.05,294,6}=0.106 ; \mathrm{p}=0.046\right)$. A. tonsa did not show significant differences in PRTs in response to any of the density gradients ( $\mathrm{df}=299, F=1.05, \mathrm{p}=$ 0.389). Individual copepods often did not cross the density gradient layer (our Fig. 6; Woodson et al. 2005), and linear regression showed a non-random distribution of residuals (Runs test, $u_{0.20(2), 6}=2, u=1$, both species) with a distinct threshold for both species. Thus, sigmoidal regression was used to estimate the response threshold. Regression of the number of individuals crossing versus magnitude of the density jump revealed a lower threshold boundary of $\Delta \sigma_{t}=0.4$ and 0.8 for
T. longicornis and A. tonsa, respectively (Fig. 6; curve begins to decrease near this value). The response to the density gradient approaches approximately $75 \%$ of the population not crossing the layer around $\Delta \sigma_{t}=2.0$ for T. longicornis and $\Delta \sigma_{t}=1.4$ for A. tonsa.

Both Temora longicornis and Acartia tonsa responded with a threshold-type response to varying concentrations of phytoplankton chemical exudates (Fig. 7). Single factor ANOVA revealed significant differences in the PRT for T. longicornis between concentration levels for both phytoplankton species (Rhodomonas lens, $F_{5,299}=10.03, \mathrm{p}<0.001$; Tetraselmis sp., $\left.F_{5,299}=13.08, \mathrm{p}<0.001\right)$. Post-hoc D-C tests revealed that PRT did not significantly increase until chemical exudate concentration reached equivalent biomass

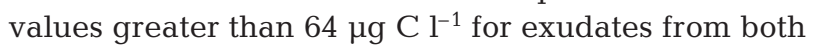
phytoplankton species. T. longicornis began to respond to $R$. lens (difference $=0.181, \mathrm{MSD}_{0.05,294,6}=$ $0.102 ; \mathrm{p}<0.001$ ) and to Tetraselmis sp. (difference $=$ $0.159, \mathrm{MSD}_{0.05,294,6}=0.101 ; \mathrm{p}<0.001$ ) at a concentration around $95 \mu \mathrm{g} \mathrm{C} \mathrm{C}^{-1}$. A. tonsa also significantly increased PRT in response to chemical exudate concentration (Fig. 7; df = 449, $F=20.87$, p $<0.001$; singlefactor ANOVA) with significant differences from the control value occurring at $158 \mu \mathrm{g} \mathrm{C} \mathrm{l}^{-1}$ (difference = $\left.0.174 ; \mathrm{MSD}_{0.05,449,1}=0.098 ; \mathrm{p}<0.001\right)$. This suggests a

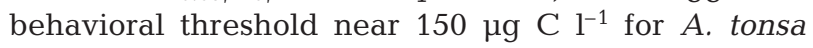
responses to Tetraselmis sp. exudates. 


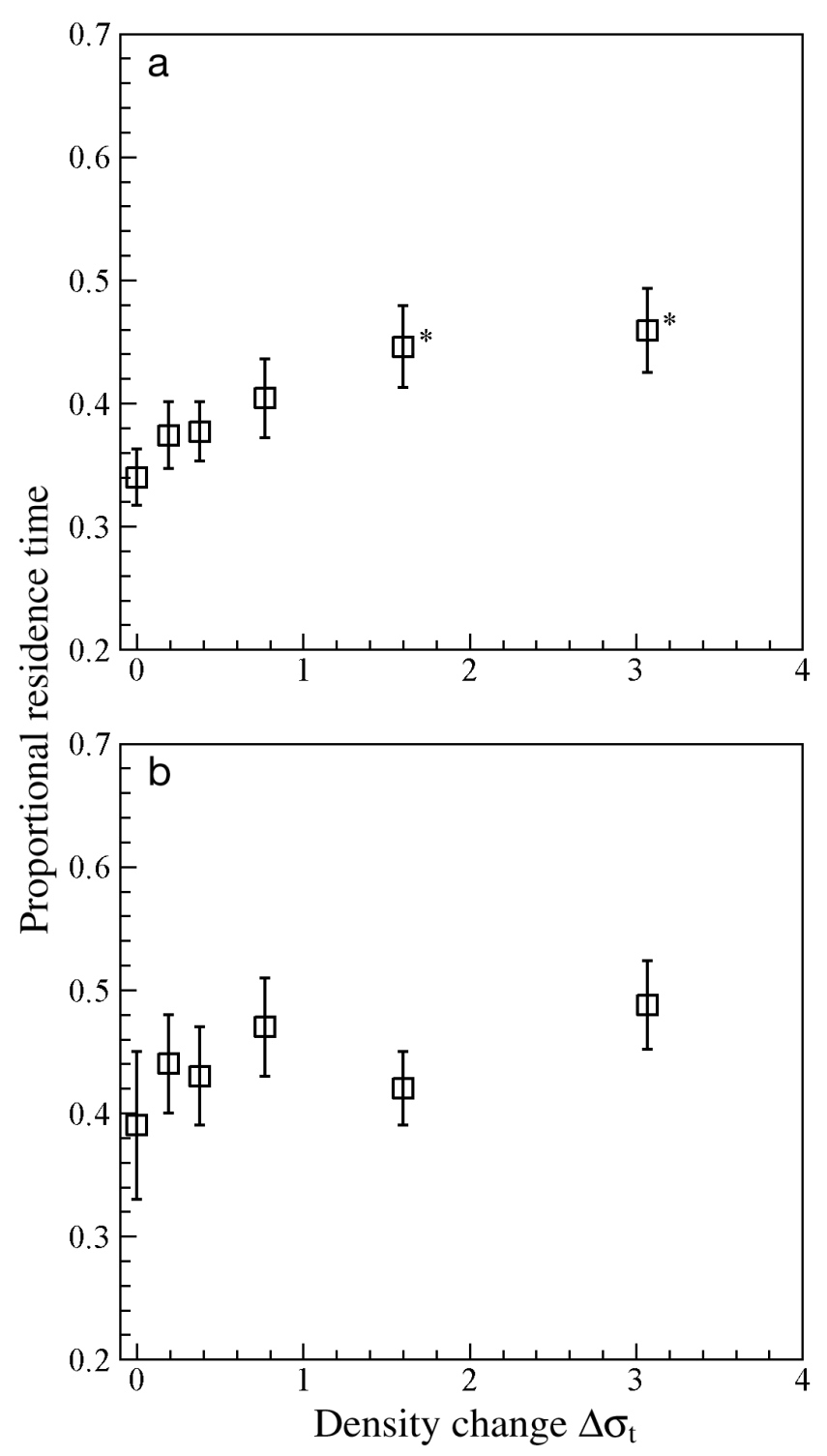

Fig. 5. Proportional residence time \pm SE for (a) Temora longicornis and (b) Acartia tonsa in response to the density gradient layer treatment with varying density jump magnitude. Density gradients are a result of a change in salinity $(0,0.25$, $0.5,1,2,4 \mathrm{ppt})$ corresponding to a change in $\Delta \sigma_{t}(0,0.2,0.4$, $0.8,1.6,3.1$, respectively). Threshold level was $\Delta \sigma_{t}=1.6$ for $T$. longicornis as defined by a significant difference (*, $\mathrm{p}<0.05)$ from control values via a Dunnett's control test (minimum significant difference, $\mathrm{MSD}_{0.05,294,6}=0.106 ; \mathrm{p}=$ 0.046). The proportional residence time for $A$. tonsa did not significantly change

Both Temora longicornis and Acartia tonsa increased swimming speed and turn frequency in response to the velocity, chemical and combined layers and showed a largely similar response pattern to the suite of treatments. Repeat measures ANOVA with post-hoc correction to reduce FDR showed significant, or strongly suggestive, increases between pre- and post-contact swimming speeds in response to velocity, chemical

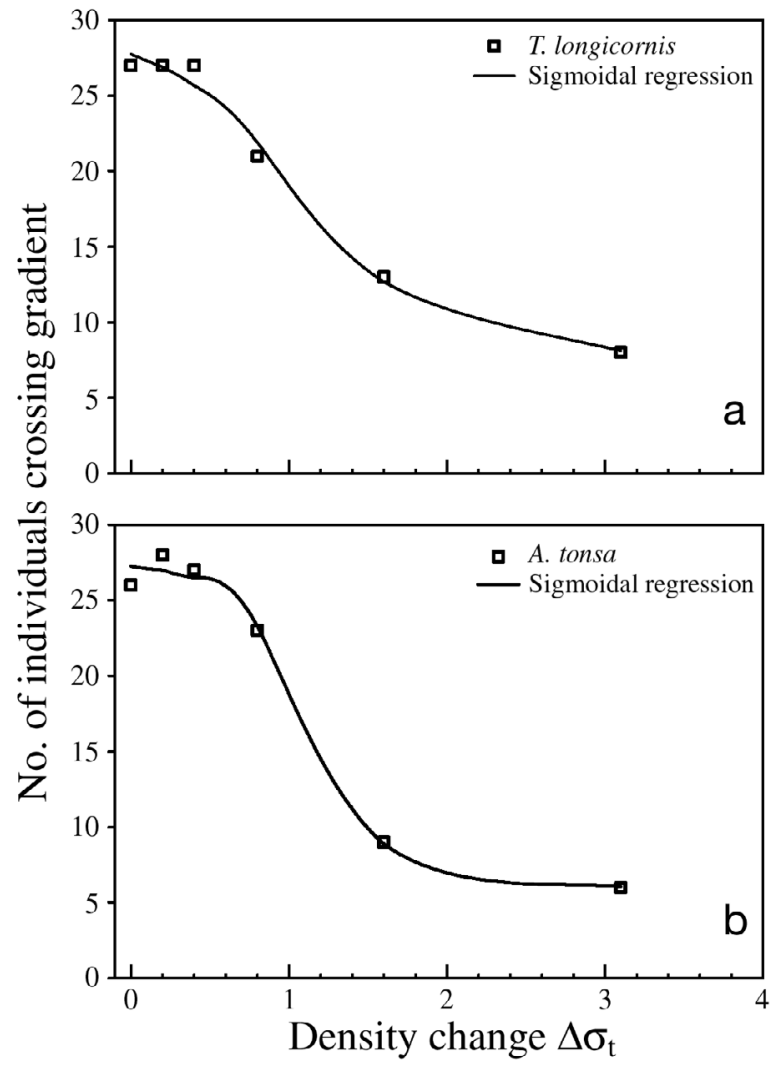

Fig. 6. (a) Temora longicornis and (b) Acartia tonsa. Behavioral response to the density gradient layer treatment represented as the number of individuals that cross the gradient layer for (a) T. longicornis $\left(\mathrm{R}^{2}=0.94, F=39.87, \mathrm{p}<0.01\right)$, and (b) A. tonsa $\left(\mathrm{R}^{2}=0.98, F=108.88, \mathrm{p}<0.01\right)$. Sample sizes are the same for all gradient levels $(\mathrm{n}=40)$. Threshold levels were $\Delta \sigma_{t}=0.4$ and 0.8 for $T$. longicornis and A. tonsa, respectively, as defined by the point where the sigmoidal curve begins to decrease

exudates and all the combination layers (Table 3) for both species. Turn frequency also increased in 6 of 8 treatments (3 of 4 for each species) with isolated velocity, isolated chemical exudates, combined velocity-chemical and all combined layers (Table 4). In contrast, the density gradient layer acted as a physical or behavioral barrier to vertical movement (Fig. 6; Woodson et al. 2005), and post-contact response values did not change in this treatment compared with pre-contact values (Tables $3 \& 4$ ). Individuals in the food layer began feeding with overall lower swimming speed and lower turn frequency due to slow $\left(<1 \mathrm{~mm} \mathrm{~s}^{-1}\right)$ horizontal movement of the organism associated with the feeding current (Tiselius 1992, C. B. Woodson pers. obs.). T. longicornis and A. tonsa did not alter pre- vs. post-contact swimming speed (Table 3) or turn frequency (Table 4) in the velocity-all chemical treatment further supporting the lack of a response to a velocity gradient in the presence of suprathreshold background concentrations of chemical exudates. 


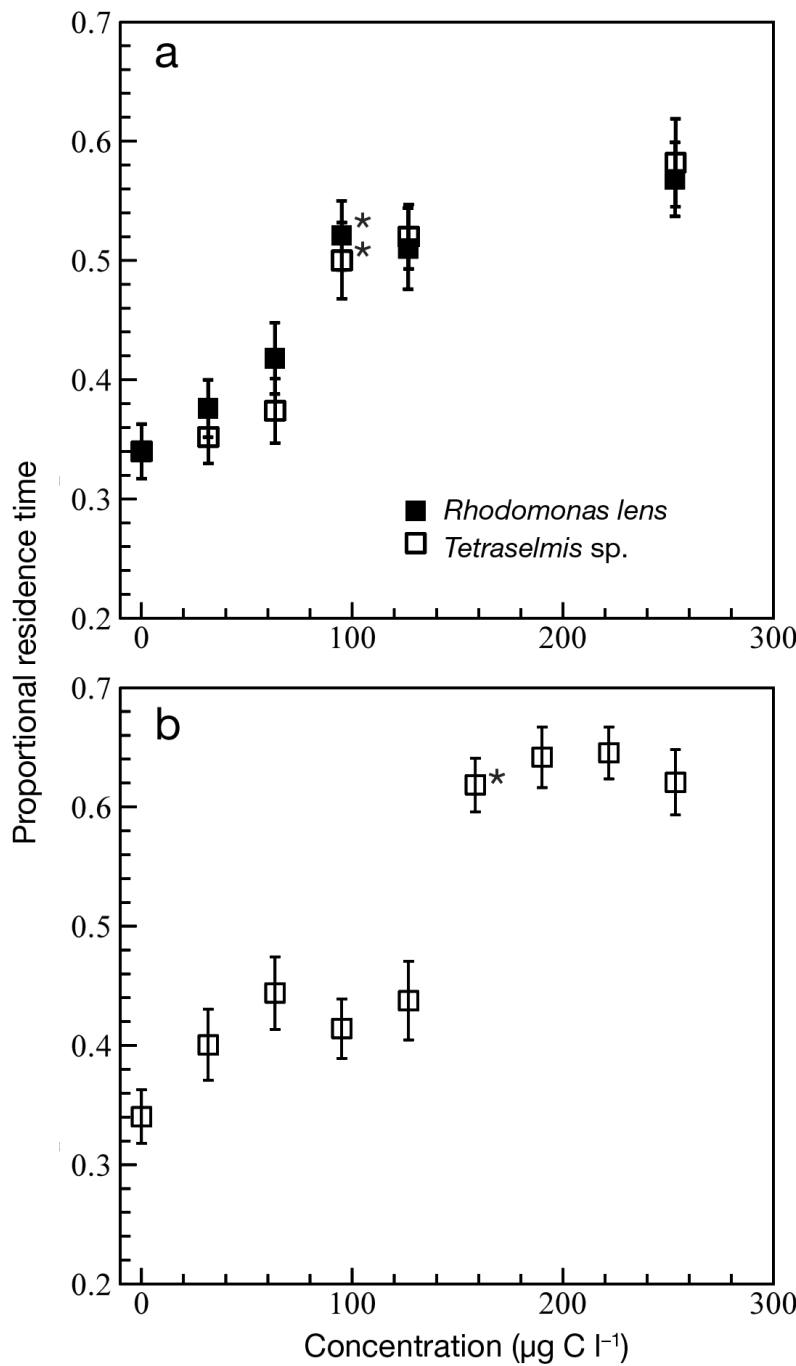

Fig. 7. (a) Temora longicornis and (b) Acartia tonsa. Proportional residence time \pm SE in the presence of the phytoplankton chemical exudate layer for (a) T. longicornis (Tetraselmis sp. and Rhodomonas lens, separately) and (b) A. tonsa (Tetraselmis sp.). Concentration of exudates was determined as equivalent cell concentration $\left(\mu \mathrm{g} \mathrm{C} \mathrm{l}^{-1}\right)$. * Significant difference $(p<0.05)$ of the treatment value compared with the preceding concentration value using a Student-NewmanKeuls post-hoc test

\section{DISCUSSION}

Aggregations of zooplankton near sharp vertical gradients of physical properties such as flow velocity or density, layers of chemicals resulting from intense phytoplankton abundance, or layers of biological activity are hypothesized to result from interplay between physical forcing and individual behavior (Franks 1995, Alldredge et al. 2002). If fine-scale patchiness in the plankton is an important feature of these habitats, some species of zooplankton may have adapted behavioral responses to features that define profitable search areas, increase foraging or mating success and ultimately improve individual fitness. In this study, the response of the calanoid copepods Temora longicornis and Acartia tonsa to various gradients associated with fine-scale oceanographic structure indicated that individuals use physical gradients and chemical exudates as cues for various behaviors. Both T. longicornis and A. tonsa individuals actively remained in both velocity gradient and chemical exudate layers employing mechanisms that were apparent in path kinematics. Increases in swimming speed and turn frequency may allow individuals to quickly and efficiently scan a region of interest for other proximal cues associated with important resources (e.g. food, mates, refugia; Cowles 2004). However, response to a velocity gradient layer may also allow zooplankton to identify regions where they can be transported (or not transported if in a low velocity region) to a new area or where they can effectively maintain both horizontal and vertical position in the water column (Genin et al. 2005, McManus et al. 2005). Responses to the combined velocity-chemical layer were different between the 2 species. T. longicornis responded positively to the velocity-chemical layer (increased PRT relative to isolated cues), suggesting that the combination enhances the response to either isolated cue. In contrast, $A$. tonsa responded aversely and decreased PRT to this combination compared with PRT to each isolated layer. Neither species increased PRT in response to a velocity gradient layer when also exposed to background chemical exudate concentrations.

Density gradients, however, elicited different responses. Individuals of both species that contacted a density gradient rarely crossed the layer, but rather swam along the layer or turned around. The observed response is not likely to be produced by salinity changes, since density gradients in the absence of a salinity change invoked similar responses in a number of zooplankton, including the copepod Temora longicornis (Harder 1968). Bochdansky \& Bollens (2004) and Ignoffo et al. (2005) reported responses for Acartia clausi and rotifers that are similar to both the present study and Harder (1968). In the present study, combining the density gradient layer with the other cues led to an increase in PRT for T. longicornis, possibly by providing a boundary to which individuals can orient and remain in the layer more effectively. However, it is also possible that the presence of an attractive cue ameliorated the aversive response to the density gradient, or was a combination of these 2 factors. The present data do not provide evidence for either case because only one concentration of each factor was tested in combined trials and the relative strengths of each layer will likely affect the balance between attraction (velocity 
Table 3. Swimming speed in all experimental treatments. Significance at ${ }^{*} p<0.10$ and ${ }^{* *} p<0.05$, between swimming speeds pre- and post-contact with the layer by repeat measures ANOVA with a post-hoc correction for multiple tests. Stimulus intensities in the combined cue treatments are at the levels reported for individual cues. Food and chemical exudate experiments were conducted with Rhodomonas lens for T. longicornis and with Tetraselmis sp. for Acartia tonsa. Data for Control, Velocity and Density for both species taken from Woodson et al. (2005). eq.: equivalent

\begin{tabular}{|c|c|c|c|c|}
\hline Treatment & $\mathrm{n}$ & $\begin{array}{l}\text { Pre-contact } \\
\text { Swimming speed }\left(\mathrm{mm} \mathrm{s}^{-1}\right) \\
\text { (SE) }\end{array}$ & $\begin{array}{l}\text { Post-contact } \\
\text { Swimming speed }\left(\mathrm{mm} \mathrm{s}^{-1}\right) \\
\text { (SE) }\end{array}$ & $\mathrm{p}$ \\
\hline \multicolumn{5}{|l|}{ Temora longicornis } \\
\hline \multicolumn{5}{|l|}{ Individual cues } \\
\hline Control & 50 & $4.50(0.22)$ & $4.76(0.47)$ & 0.68 \\
\hline Velocity $\left(U_{j}=6.7 \mathrm{~mm} \mathrm{~s}^{-1}\right)$ & 46 & $5.40(0.41)$ & $6.84(0.51)$ & $0.031^{* *}$ \\
\hline Density $\left(\Delta \sigma_{t}=1.6\right)$ & 48 & $5.37(0.24)$ & $5.36(0.19)$ & 0.990 \\
\hline Chemical (253 $\mu \mathrm{g} \mathrm{C}^{-1}$ eq.) & 40 & $2.41(0.15)$ & $3.72(0.38)$ & $0.019^{* *}$ \\
\hline Food $\left(253 \mu \mathrm{g} \mathrm{Cl}^{-1}\right)$ & 42 & $3.57(0.32)$ & $2.71(0.17)$ & $0.078^{*}$ \\
\hline \multicolumn{5}{|l|}{ Combined cues } \\
\hline Velocity-Density & 50 & $5.13(0.40)$ & $6.53(0.47)$ & $0.056^{*}$ \\
\hline Velocity-Chemical & 37 & $3.17(0.31)$ & $4.55(0.36)$ & $0.064^{*}$ \\
\hline Density-Chemical & 41 & $3.31(0.29)$ & $3.97(0.15)$ & $0.075^{*}$ \\
\hline Velocity-Density-Chemical & 47 & $4.44(0.41)$ & $5.51(0.30)$ & $0.083^{*}$ \\
\hline Velocity-All Chemical & 42 & $5.54(0.48)$ & $5.36(0.64)$ & 0.858 \\
\hline \multicolumn{5}{|l|}{ Acartia tonsa } \\
\hline \multicolumn{5}{|l|}{ Individual cues } \\
\hline Control & 47 & $2.23(0.17)$ & $2.15(0.15)$ & 0.787 \\
\hline Velocity $\left(U_{j}=6.7 \mathrm{~mm} \mathrm{~s}^{-1}\right)$ & 47 & $3.08(0.17)$ & $3.68(0.19)$ & $0.046^{* *}$ \\
\hline Density $\left(\Delta \sigma_{t}=1.6\right)$ & 48 & $1.82(0.07)$ & $1.71(0.06)$ & 0.561 \\
\hline 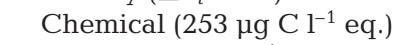 & 40 & $1.91(0.18)$ & $2.57(0.14)$ & $0.048^{* *}$ \\
\hline Food $\left(253 \mu \mathrm{g} \mathrm{C} \mathrm{l}^{-1}\right)$ & 42 & $2.85(0.19)$ & $1.97(0.17)$ & $0.036^{* *}$ \\
\hline \multicolumn{5}{|l|}{ Combined cues } \\
\hline Velocity-Density & 50 & $3.04(0.38)$ & $3.93(0.22)$ & $0.075^{*}$ \\
\hline Velocity-Chemical & 40 & $2.28(0.20)$ & $3.09(0.25)$ & $0.062^{*}$ \\
\hline Density-Chemical & 41 & $2.55(0.15)$ & $3.05(0.17)$ & $0.087^{*}$ \\
\hline Velocity-Density-Chemical & 36 & $3.13(0.29)$ & $4.37(0.26)$ & $0.054^{*}$ \\
\hline Velocity-All Chemical & 43 & $2.75(0.15)$ & $2.59(0.14)$ & 0.573 \\
\hline
\end{tabular}

and chemical exudates) and aversion (density). In contrast, A. tonsa did not alter responses to other cues when a density gradient was present. Possible reasons that relate to this phenomenon include a wider salinity tolerance range for $A$. tonsa and the greater variability of temperature and salinity in the estuarine systems preferred by $A$. tonsa. The frequent failure of both $T$. longicornis and $A$. tonsa to cross the density gradient layer (Fig. 6) suggests that copepods can detect the layer, but it does not indicate a potential source of food. However, in the absence of a velocity gradient, $T$. longicornis still aggregates near density gradients (Harder 1968, increased PRT in Woodson et al. 2005). In density-only treatments, the copepods do not cross the density gradient, and accumulate at the layer edge. These observations suggest that not all copepod aggregations may result from attraction, and that the balance between attractive and potentially aversive or restrictive conditions is important in determining the overall response of motile organisms to ocean structure.

\section{Excited area-restricted search}

Tinbergen et al. (1967) suggested that distribution patterns for organisms could be partially explained by the use of an area-restricted search strategy, which was later defined as more frequent turning and slower movement by a predator (e.g. Leising \& Franks 2002), but was left open to other potential mechanisms in the original work. The consequent impact of arearestricted search on distributions in the plankton was discussed in Hamner (1988) and Leising \& Franks (2000) as a mechanism for aggregation. Tiselius (1992) and Saiz et al. (1993) provided examples of the impacts of patchiness on the copepod Acartia tonsa. More recently, Leising \& Franks (2002) proposed classic area-restricted search strategy for Acartia clausi as a means of dealing with resource patchiness at small spatial and temporal scales (e.g. cm, min). Although an individual could adequately remain within a patch for time periods sufficient to fill a gut by slowing down (e.g. feeding), the individual must first be able to locate 
Table 4. Turn frequency in all experimental treatments. Significance at ${ }^{*} p<0.10$ and ${ }^{* *} p<0.05$, between turn frequencies precontact and post-contact with the layer by repeat measures ANOVA with a post-hoc correction for multiple tests. Stimulus intensities in the combined cue treatments are at the levels reported for individual cues. Food and chemical exudate experiments were conducted with Rhodomonas lens for Temora longicornis and with Tetraselmis sp. for Acartia tonsa. Data for Control, Velocity and Density for both species taken from Woodson et al. (2005). eq.: equivalent

\begin{tabular}{|c|c|c|c|c|}
\hline Treatment & $\mathrm{n}$ & $\begin{array}{l}\text { Pre-contact } \\
\text { (no. turns ind } .^{-1} \mathrm{~s}^{-1} \text { ) } \\
\text { (SE) }\end{array}$ & $\begin{array}{c}\text { Post-contact } \\
\text { (no. turns ind } .^{-1} \mathrm{~s}^{-1} \text { ) } \\
\text { (SE) }\end{array}$ & $\mathrm{p}$ \\
\hline \multicolumn{5}{|l|}{ Temora longicornis } \\
\hline \multicolumn{5}{|l|}{ Individual cues } \\
\hline Control & 40 & $0.11(0.01)$ & $0.10(0.02)$ & 0.801 \\
\hline Velocity $\left(U_{j}=6.7 \mathrm{~mm} \mathrm{~s}^{-1}\right)$ & 40 & $0.10(0.02)$ & $0.24(0.06)$ & $0.073^{*}$ \\
\hline Density $\left(\Delta \sigma_{t}=1.6\right)$ & 40 & $0.14(0.03)$ & $0.13(0.04)$ & 0.863 \\
\hline Chemical (253 $\mu{\mathrm{g} \mathrm{C} \mathrm{l}^{-1} \text { eq.) }}$ & 40 & $0.11(0.04)$ & $0.23(0.04)$ & $0.082^{*}$ \\
\hline Food $\left(253 \mu \mathrm{g} \mathrm{C}^{-1}\right)$ & 40 & $0.11(0.04)$ & $0.16(0.03)$ & 0.394 \\
\hline \multicolumn{5}{|l|}{ Combined cues } \\
\hline Velocity-Density & 40 & $0.06(0.03)$ & $0.22(0.04)$ & $0.048^{* *}$ \\
\hline Velocity-Chemical & 37 & $0.12(0.05)$ & $0.22(0.06)$ & 0.256 \\
\hline Density-Chemical & 40 & $0.10(0.03)$ & $0.22(0.04)$ & $0.084^{*}$ \\
\hline Velocity-Density-Chemical & 40 & $0.08(0.03)$ & $0.19(0.03)$ & $0.075^{*}$ \\
\hline Velocity-All Chemical & 40 & $0.20(0.02)$ & $0.19(0.04)$ & 0.676 \\
\hline \multicolumn{5}{|l|}{ Acartia tonsa } \\
\hline \multicolumn{5}{|l|}{ Individual cues } \\
\hline Control & 40 & $0.05(0.02)$ & $0.07(0.02)$ & 0.61 \\
\hline Velocity $\left(U_{j}=6.7 \mathrm{mms}^{-1}\right)$ & 40 & $0.09(0.02)$ & $0.24(0.05)$ & $0.055^{*}$ \\
\hline Density $\left(\Delta \sigma_{t}=1.6\right)$ & 40 & $0.06(0.02)$ & $0.08(0.03)$ & 0.682 \\
\hline Chemical (253 $\mu \mathrm{g} \mathrm{C} \mathrm{l}^{-1}$ eq.) & 40 & $0.02(0.02)$ & $0.20(0.04)$ & $0.067^{*}$ \\
\hline Food $\left(253 \mu \mathrm{g} \mathrm{Cl}^{-1}\right)$ & 40 & $0.06(0.04)$ & $0.10(0.03)$ & 0.644 \\
\hline \multicolumn{5}{|l|}{ Combined cues } \\
\hline Velocity-Density & 34 & $0.03(0.02)$ & $0.10(0.02)$ & 0.112 \\
\hline Velocity-Chemical & 37 & $0.04(0.02)$ & $0.09(0.02)$ & 0.124 \\
\hline Density-Chemical & 40 & $0.04(0.01)$ & $0.09(0.04)$ & $0.077^{*}$ \\
\hline Velocity-Density-Chemical & 36 & $0.02(0.01)$ & $0.07(0.02)$ & $0.065^{*}$ \\
\hline Velocity-All Chemical & 37 & $0.12(0.03)$ & $0.11(0.02)$ & 0.665 \\
\hline
\end{tabular}

an adequate resource patch such that 'the total integrated foraging behavior of a planktonic organism is probably a combination of different behaviors, specific for different scales' (Leising \& Franks 2002). The scales associated with locating thin layer patches are smaller than large-scale movements such as diel vertical migration (e.g. ranging tens of meters) and larger than micro-scale behaviors such as feeding $(\mathrm{cm}$ B Bell 1989; Leising \& Franks 2002).

Results of the present study agree with search theory at multiple scales (Bell 1989, Dusenbery 1992) because copepods increased swimming speed when they sensed cues indicative of resource patches, but slowed and began feeding in the presence of food particles. Faster movement is ideal for animals searching for food using an associated cue because search time is inversely proportional to the movement of the organism:

$$
t_{\mathrm{c}}=2 d^{2} / r_{\mathrm{d}} V_{\mathrm{f}}
$$

where $t_{\mathrm{c}}$ is the mean time to locate a patch, $d$ is the half-distance between patches, $r_{\mathrm{d}}$ is the response dis- tance of the forager, and $v_{\mathrm{f}}$ is the speed of the forager (Bell 1989, Dusenbery 1992). However, maintaining high speeds for long periods is often energetically costly. Hence, excited area-restricted search behavior (focused bouts of increased speed and turn frequency, Woodson et al. 2005) in response to environmental cues increases the probability of locating resource patches at intermediate scales while minimizing energetic expenditure. Conversely, when located in a food patch, copepods should stay in one place and, hence, reduce swimming speed (present study, also Tiselius 1992, Leising \& Franks 2002).

Successful intermediate-scale search behavior and patch location is not dependent on prey concentration. However, the concentration of prey (or degree of association of a cue with prey) determines the length and intensity of searching and feeding (if at all). By employing cue association and prey concentration in this fashion a forager can minimize both time spent in low quality patches and time searching for new more productive patches. This mechanism is supported by the 
threshold response to chemical exudate concentration (Fig. 7) and the observation that both species of copepods ceased excited area-restricted search response after a period when food particles were not located.

\section{Cue hierarchy}

Our data suggest that copepods in the ocean use search strategies that employ multiple cues. Such strategies are well known for terrestrial arthropods that use a suite of cues to improve search success and foraging efficiency by employing information hierarchies to consecutively narrow search regions (Vet 1999). Animals employ cue hierarchies in response to a reliability-detectability dilemma, where reliability is defined as the degree of association with the search target, and detectability is defined as the availability of a cue at specific scales. For example, many insects use visual, chemical and physical cues to progressively focus search regions until a host or mate is found (Tumlinson et al. 1993). Perception is dominated at long range by visual cues or chemical volatiles from associated plants, at intermediate scales by scents of fruiting bodies near a potential host site and at close range by host-specific cues (Vinson et al. 1987, Tumlinson et al. 1993).

In the ocean, physical and biological structures are often closely related since physical oceanographic forces such as currents, swells, and tides (physical forcing) directly impacts biological patchiness (e.g. Franks 1995). For example, thin plankton layers have been documented most extensively in coastal regions along the west coast of North America (Cowles 2004). However, recent observations reveal these features may not be geographically restricted and probably occur throughout the world's oceans (McManus et al. 2005). Field observations of thin layers and other fine-scale oceanographic structures suggest that associations between flow velocity gradients, density changes and biological activity may provide zooplankton with spatial and temporal information that profoundly affects foraging behavior and success. More than $75 \%$ of the phytoplankton biomass within the upper $25 \mathrm{~m}$ of the water column can be concentrated into thin layers that are roughly 1 to $4 \mathrm{~m}$ thick (Holliday et al. 1998, Cowles 2004). Thus, phytoplankton concentrations that are adequate to support zooplankton populations may be present in as little as 4 to $16 \%$ of the habitat (Cowles 2004) depending on various factors such as layer concentration, layer thicknesses and copepod physiology. In contrast, velocity gradient layers can cover 15 to $25 \%$ of the water column (Dekshenieks et al. 2001, Cowles 2004). In its search for food an individual that narrows search regions by progressively using associated velocity and chemical gradients considerably decreases the total area to be searched and accordingly directs the search to areas that are more likely to contain food. Thus, a copepod improves foraging efficiency simply by increasing the probability of a food encounter and limiting energetic expenditure as shown in Fig. 8. Oceanographic structure, hence, provides dynamic cues for identifying and searching a region of interest, suggesting that systematic use of these cues enhances resource location. Thus, physical gradients could signal the potential presence of a biological layer and encourage brief focused searches for other information.

Our observations of Temora longicornis responses to isolated and combined layers support a cue hierarchy that begins with gradients in flow velocity, continues to waterborne chemical exudates and culminates in feeding behavior in response to cell contact or perception of more specific chemical cues (i.e. the scheme proposed in Fig. 8). Chemical cues increase PRT more than velocity gradients, but responses to the combined velocity-chemical layer were stronger than either cue alone. Additionally, chemical exudates appear more important as foraging cues because responses to velocity gradients were negated in favor of chemical exudates in the velocity-all chemical treatment. Chemical cues emanating from potential food are, in general, much more accurate cues to resource density and location, and, hence, should rank more strongly in the cue

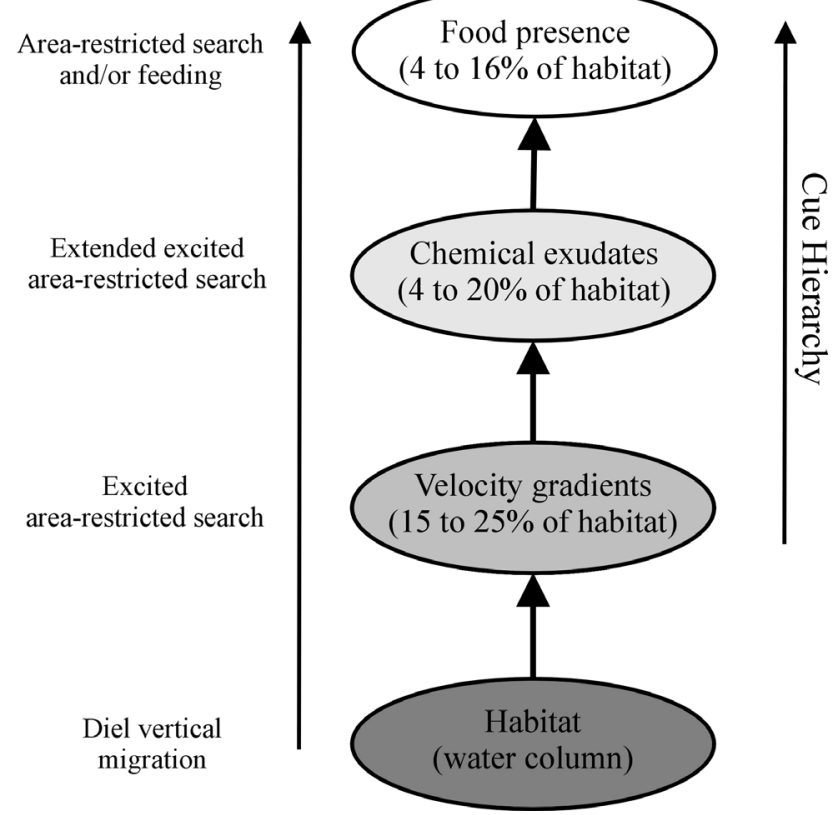

Fig. 8. Temora longicornis and Acartia tonsa. Proposed cue hierarchy for copepod foraging based on results of the present study. Percentages are based on in situ data reported in the thin layers literature (Holliday et al. 1998, Dekshenieks et al. 2001, McManus et al. 2003, Cowles 2004) 
hierarchy than velocity gradients alone. By concentrating local searches near regions of closely associated factors (velocity gradients and biological activity), $T$. longicornis is able to enhance search success, while minimizing the energetic expenditure associated with patch location.

Acartia tonsa may also use velocity gradients as a cue to increase search intensity. However, the roughly equal responses to the individual cues and the lack of a stronger combined effect suggest the lack of a strictly delineated hierarchy as seen in Temora longicornis. Even so, A. tonsa responses to isolated velocity gradients (higher PRT) are modified, albeit weakly, by the presence of chemical exudates.

Responses by Acartia tonsa and Temora longicornis to velocity and chemical gradients appear to be functional cues in a cue hierarchy. However, responses to velocity gradients may also be related to position maintenance as seen in other zooplankton (e.g. Genin et al. 2005, McManus et al. 2005) and not always directly linked to foraging. Observations of increased relative swimming speed in the velocity gradient layer support this mechanism, but the lack of response in the presence of chemical exudates suggests that although position maintenance may be employed, velocity gradients are also employed in foraging behaviors. Determining the relative importance of such cues and how they are predominately employed will be fundamental in correlating behavior with observed distribution patterns.

\section{Species-specific behavior}

Behavioral studies demonstrate acute chemosensitivity in Temora longicornis (Doall et al. 1998) and acute mechanosensitivity in Acartia sp. (Tiselius \& Jonsson 1990). Morphological analysis of the sensory organ, the antennules, shows long hair-like setae on Acartia tonsa, which are considered mechanoreceptive (Kiørboe et al. 1999). Setal sensors on T. longicornis are shorter and planar in distribution along its antennule and likely less useful for 3-dimensional positional analyses of discrete fluid mechanical signals (Gill 1986, Mauchline 1998). These differences in sensitivity to cues of different modality agree well with our findings of species-specific responses to thin layer cues when offered in isolation or combined. T. longicornis showed stronger responses when both fluid mechanical and chemicals were present, whereas $A$. tonsa showed the same intensity in its responses regardless of which cue was present or whether they were combined.

These physiological differences and our observations suggest functionally different responses to signals that may be contingent on habitat characteristics. For example, although both of these species are found in coastal regions, Acartia tonsa frequents estuarine habitats that are often dominated by freshwater inputs and significant mixing, and the animal has a higher probability of being swept offshore (e.g. Wassaw Sound, Georgia, Tiselius 1992). In contrast, Temora longicornis prefers regions not dominated by freshwater input where velocity gradients and resources may be more closely aligned (e.g. Stony Brook Harbor, New York, Doall et al. 1998). Thus, the velocity gradient layer may not be a good indicator of habitat quality in some systems, but instead could be used as a cue for copepods to remain in a particular area in order to avoid being swept offshore.

\section{CONCLUSIONS}

Cue hierarchy is a common mechanism used by zooplankton for consecutively narrowing search regions, but it has not been previously investigated in the Copepoda (Mauchline 1998, Vet 1999). Further, studies where individual cues can be isolated and combined in a controlled fashion to analyze relative importance are rare in both terrestrial and marine systems. The use of cue hierarchy in foraging behaviour and velocity gradients in position maintenance by Temora longicornis, Acartia tonsa, and other zooplankton (Genin et al. 2005), support suggestions that behavior plays an important role in aggregation and patchiness of zooplankton populations in the ocean. Hence, zooplankton behavior at intermediate scales may impact higher trophic levels (Wishner et al. 1995) and influence larger scale processes such as dispersal and recruitment (Cowen et al. 2006). A continued drive toward understanding and answering these questions will benefit from collaborations between interdisciplinary field studies, laboratory investigations and modeling efforts where specific aspects of the environment can be accurately isolated, controlled or analyzed.

Acknowledgements. This research was funded by Office of Naval Research grant N000140310366 and an NSF-IGERT fellowship awarded to C.B.W. Special thanks to M. Doall, J. Levinton, J. Mackie (State University of New York-Stony Brook), D. M. Fields (Bigelow Marine Lab), M. J. Ferner (Skidaway Institute of Oceanography), C. Manning (University of New Hampshire), P. Hobson, and B. McArdle (Georgia Institute of Technology) for animal collection, culture maintenance and experimental setup.

\section{LITERATURE CITED}

Alldredge AL, Cowles TJ, MacIntyre S, Rines JEB and 6 others (2002) Occurrence and mechanisms of formation of a dramatic thin layer of marine snow in a shallow Pacific fjord. Mar Ecol Prog Ser 233:1-12 
Bainbridge R (1953) Studies on the interrelationships of zooplankton and phytoplankton. J Mar Biol Assoc UK 32: 385-447

Bell WJ (1989) Searching behaviour: the behavioural ecology of finding resources. Chapman \& Hall, London

Benjamini Y, Hochberg Y (1995) Controlling the false discovery rate: a practical and powerful approach to multiple testing. J R Stat Soc B 57:289-300

Bochdansky AB, Bollens SM (2004) Relevant scales in zooplankton ecology: distribution, feeding, and reproduction of the copepod Acartia hudsonica in response to thin layers of the diatom Skeletonema costatum. Limnol Oceanogr 49:625-636

Clay TW, Bollens SM, Bochdansky AB, Ignoffo TR (2004) The effects of thin layers on the vertical distribution of larval Pacific herring, Clupea pallasi. J Exp Mar Biol Ecol 305: 171-189

Cowen RK, Paris CB, Srinivasan A (2006) Scaling of connectivity in marine populations. Science 311:522-527

Cowles TJ (2004) Planktonic layers: physical and biological interactions on the small scale. In: Seuront L, Strutton PG (eds) Handbook of scaling methods in aquatic ecology: measurements, analysis, simulation. CRC Press, Boca Raton, FL, p 31-49

Daro MH (1988) Migratory and grazing behavior of copepods and vertical distribution of phytoplankton. Bull Mar Sci 43: 710-729

Dekshenieks MM, Donaghay PL, Sullivan JM, Rines JEB, Osborn TR, Twardowski MS (2001) Temporal and spatial occurrence of thin phytoplankton layers in relation to physical processes. Mar Ecol Prog Ser 223:61-71

Doall MH, Colin SP, Strickler JR, Yen J (1998) Locating a mate in 3D: the case of Temora longicornis. Philos Trans R Soc Lond B 353:681-689

Dusenbery DB (1992) Sensory ecology: how organisms acquire and respond to information. WH Freeman, New York

Fields DM, Yen J (1997) The escape behavior of marine copepods in response to a quantifiable fluid mechanical disturbance. J Plankton Res 19:1289-1304

Fields DM, Shaeffer DS, Weissburg MJ (2002) Mechanical and neural responses from the mechanosensory hairs on the antennule of Gaussia princeps. Mar Ecol Prog Ser 227: 173-186

Franks PJS (1995) Thin-layers of phytoplankton-a model of formation by near-inertial wave shear. Deep-Sea Res I 42: 75-91

Gallager SM, Yamazaki H, Davis CS (2004) Contribution of fine-scale vertical structure and swimming behavior to formation of plankton layers on Georges Bank. Mar Ecol Prog Ser 267:27-43

Genin A, Jaffe JS, Reef R, Richter C, Franks PJS (2005) Swimming against the flow: a mechanism of zooplankton aggregation. Science 308:860-862

Gill CW (1986) Suspected mechanosensory and chemosensory structures of Temora longicornis (Copepoda, Calanoida). Mar Biol 93:449-457

Hamner WM (1988) Behavior of plankton and patch formation in pelagic ecosystems. Bull Mar Sci 43:752-757

Hansen BW, Nielsen TG, Levinsen H (1999) Plankton community structure and carbon cycling on the western coast of Greenland during the stratified summer situation. III. Mesozooplankton. Aquat Microb Ecol 16:233-249

Harder W (1968) Reactions of plankton organisms to water stratification. Limnol Oceanogr 13:156-168

Holliday DV, Pieper RE, Greenlaw CF, Dawson JK (1998) Acoustical sensing of small-scale vertical structures in zooplankton assemblages. Oceanography 11:18-23
Holliday DV, Donaghay PL, Greenlaw CF, McGehee DE, McManus MM, Sullivan JM, Mikiss JL (2003) Advances in defining fine- and micro-scale pattern in marine plankton. Aquat Living Resour 16:131-136

Ignoffo TR, Bollens SM, Bochdansky AB (2005) The effects of thin layers on the vertical distribution of the rotifer, Brachionus plicatilis. J Exp Mar Biol Ecol 316:167-181

Kiørboe, T, Saiz E, Visser A (1999) Hydrodynamic signal perception in the copepod Acartia tonsa. Mar Ecol Prog Ser 179:97-111

Landry MR, Lorenzen CJ, Peterson WK (1994) Mesozooplankton grazing in the Southern California Bight. 2. Grazing impact and particulate flux. Mar Ecol Prog Ser 115:73-85

Leising AW (2001) Copepod foraging in patchy habitats and thin layers using a 2-D individual-based model. Mar Ecol Prog Ser 216:167-179

Leising AW, Franks PJS (2000) Copepod vertical distribution within a spatially variable food source: a simple foragingstrategy model. J Plankton Res 22:999-1024

Leising AW, Franks PJS (2002) Does Acartia clausi (Copepoda: Calanoida) use an area-restricted search foraging strategy to find food? Hydrobiologia 480:193-207

Mackas DL, Louttit GC (1988) Aggregation of the copepod Neocalanus plumchrus at the margin of the Fraser River plume in the Strait of Georgia. Bull Mar Sci 43:810-824

Mauchline J (1998) The biology of calanoid copepods. Elsevier Academic Press, San Diego, CA

McManus MA, Alldredge AL, Barnard AH, Boss E and 21 others (2003) Characteristics, distributions and persistence of thin layers over a 48 hour period. Mar Ecol Prog Ser 261: $1-19$

McManus MA, Cheriton OM, Drake PJ, Holliday DV, Storlazzi CD, Donaghay PL, Greenlaw CE (2005) The effects of physical processes on the structure and transport of thin zooplankton layers in the coastal ocean. Mar Ecol Prog Ser 301:199-215

Menden-Deuer S, Lessard EJ (2000) Carbon to volume relationships for dinoflagellates, diatoms, and other protist plankton. Limnol Oceanogr 45:569-579

Mullin MM, Brooks ER (1976) Some consequences of distributional heterogeneity of phytoplankton and zooplankton. Limnol Oceanogr 21:784-796

Poulet SA, Marsot P (1978) Chemosensory grazing by marine calanoid copepods (Arthropoda Crustacea). Science 200: 1403-1405

Saiz E, Tiselius P, Jonssen PR, Verity P, Paffenhofer GA (1993) Experimental records of the effects of food patchiness and predation on egg production of Acartia tonsa. Limnol Oceanogr 38:280-289

Stearns DE, Forward RB Jr (1984) Photosensitivity of the calanoid copepod Acartia tonsa. Mar Biol 82:85-89

Tinbergen N, Impekoven M, Franck D (1967) An experiment on spacing-out as a defense against predation. Behavior 28:307-321

Tiselius P (1992) Behavior of Acartia tonsa in patchy food environments. Limnol Oceanogr 37:1640-1651

Tiselius P, Jonsson PR (1990) Foraging behavior of six calanoid copepods: observations and hydrodynamic analysis. Mar Ecol Prog Ser 66:23-33

Titelman J (2001) Swimming and escape behavior of copepod nauplii: implications for predator-prey interactions among copepods. Mar Ecol Prog Ser 213:203-213

Tumlinson JH, Lewis WJ, Vet LEM (1993) How parasitic wasps find their hosts. Sci Am 268:100-106

Turner JT (2004) The importance of small planktonic copepods and their roles in pelagic marine food webs. Zool Stud 43:255-266 
Vet LEM (1999) From chemical to population ecology: infochemical use in an evolutionary context. J Chem Ecol 25:31-49

Vinson SB, Elzen GW, Williams HJ (1987) The influence of volatile plant allelochemics on the third trophic level (parasitoids) and their herbivorous hosts. In: Labeyrie V, Fabres G, Lachaise DW (eds) Insects-plants. Junk Publishers, Hingham, MA, p 109-114

Widder EA, Johnsen S, Bernstein SA, Case JF, Neilson DJ (1999) Thin layers of bioluminescent copepods found at density discontinuities in the water column. Mar Biol 134: 429-437

Wishner KF, Schoenherr JR, Beardsley R, Chen CS (1995) Abundance, distribution and population structure of the

Editorial responsibility: Howard Browman (Associate Editorin-Chief), Storebø, Norway copepod, Calanus finmarchicus, in a springtime Right whale feeding area in the southwestern Gulf of Maine. Cont Shelf Res 15:475-507

Woodson CB, Webster DR, Weissburg MJ, Yen J (2005) Response of copepods to physical gradients associated with structure in the ocean. Limnol Oceanogr 50: 1552-1564

Yen J, Fields DM (1992) Escape responses of Acartia hudsonica (Copepoda) nauplii from the flow field of Temora longicornis (Copepoda). Arch Hydrobiol Beih Ergeb Limnol 36:123-134

Zar JH (1999) Biostatistical analysis. Prentice Hall, Upper Saddle River, NJ

Submitted: April 5, 2006; Accepted: June 13, 2006

Proofs received from author(s): January 12, 2007 